\title{
Çevrimiçi Kütüphane Kataloglarına Yönelik Kullanıcı Beklentileri: Ankara Üniversitesi ve Hacettepe Üniversitesi Kütüphaneleri Örneği*
}

\author{
User Expectations on Online Library Catalogs: \\ Ankara University and Hacettepe University Libraries
}

\author{
Nevzat ÖZEL ${ }^{* *}$ ve Tolga ÇAKMAK***
}

\begin{abstract}
Öz
Gelişen web teknolojileri, bilgi kaynaklarına erişimde önemli bir role sahip olan çevrimiçi kütüphane kataloglarının işlevlerinin artıılmasına ve yeni nesil kütüphane kataloglarının oluşturulmasına katkı sağlamaktadır. Etkileşim, paylaşım ve katılımı ön planda tutan yeni nesil kütüphane katalogları, geliştirilen özellikleriyle kullanıcıların bilgi kaynaklarına erişimlerinde ve bu kaynakları kullanımlarında önemli bir etki yaratmaktadır. Bu çalışmada, kullanıcıları bilgi arama davranışlarından hareket ederek, onların çevrimiçi kütüphane kataloglarını kullanma biçimlerini belirlemek ve bu kataloglara sosyal ağ özelliklerinin kazandırılması ile ilgili gereksinimlerini/ beklentilerini saptamak amaçlanmıştır. Betimleme yönteminin kullanıldığı çalışma kapsamında, Ankara Üniversitesi ve Hacettepe Üniversitesi'nden toplam 179 kişiyle yapılandırılmış görüşme gerçekleştirilmiştir. Çalışma sonucunda, kullanıcıların bilimsel bilgi arama davranışlarında ilk olarak arama motorlarına başvurdukları; kütüphane kataloglarını üçüncü sırada tercih ettikleri; kütüphane kataloglarında çoğunlukla kaynakların içeriklerine erişim sağlayan bilgileri görmek istedikleri ve erişim için fasat yapılar ve heceleme algoritmaları gibi unsurları önemsedikleri belirlenmiştir.
\end{abstract}

Anahtar sözcükler:Kütüphane katalogları, Sosyal ağlar, Kütüphane 2.0, Kullanıcı beklentileri, Kullanıcı araştırmaları.

\footnotetext{
Bu makale, "The 3rd IEEE/ACM International Conference on Cyber, Physical and Social Computing (CPSCom-2010)" adlı konferansta (18-20 Aralık 2010, Hangzhou, Çin) sunulan bildirinin genişletilmiş ve Türkçeleştirilmiş biçimidir.

** Arş.Gör.; Ankara Üniversitesi Dil ve Tarih-Coğrafya Fakültesi Bilgi ve Belge Yönetimi Bölümü, Ankara. (nozel@ humanity.ankara.edu.tr)

*** Arş.Gör.; Hacettepe Üniversitesi Edebiyat Fakültesi Bilgi ve Belge Yönetimi Bölümü, Ankara. (tcakmak@hacettepe. edu.tr)
} 


\begin{abstract}
Developing web-technologies contribute to the formation of the next generation library catalogs by increasing functions of the online library catalogs, which has an important role in access to information resources. With their improved features, the next-generation library catalogs, keeping interaction, sharing, and participation in the forefront, creates a significant impact on users' access to information sources and using of these resources. In this study, the aim is to determine the way of user utilization of online library catalogs by means of their information seeking behavior and to indicate their needs/expectations about bringing social networking features to these catalogs. Within the scope of the study, where a descriptive method was used, structured interviews were conducted among 179 users in Ankara University and Hacettepe University. The results of the study shows that users first applied to search engines in their information search behavior. They preferred library catalogs at the third place They mostly want to see the information providing access to contents of resources in library catalogs, and pay special attention to the elements such as faceted structures and spelling algorithms for access.
\end{abstract}

Keywords: Library catalogs, Social networks, Library 2.0, User expectations, User studies.

\title{
Giriş
}

Web 2.0 teknolojileri, paylaşım ve katılım esasına dayanan bir iletişim ortamını web kullanıcılarına sunmakta; günümüzde farklı disiplinlere yönelik olarak tasarlanan çoğu web uygulamalarında da önemli bir etki yaratmaktadır. Etkileşime olanak sağlayan bu yeni iletişim ortamlarındaki sosyal ağ uygulamaları sayesinde bireyler, web içeriklerine katkıda bulunabilmekte ve bu içerikleri kolaylıkla kullanabilmektedir. Kullanıcıların yeni sistemlerle olan etkileşimi, onların sistemlere karşı farklı beklenti ve gereksinimlerinin oluşmasına neden olmaktadır.

Teknolojide yaşanan tüm gelişmelerden doğrudan etkilenen kütüphaneler de, kullanıcı merkezli bu yeni iletişim ortamlarına karşı duyarsız kalmamakta; kendi kullanıcılarının beklentileri ve gereksinimleri doğrultusunda hizmetlerini bu ortamlarda da sürdürme eğilimi taşımaktadırlar. Web 2.0 teknolojilerinin sağladığı tüm olanaklar (sosyal ağlar, bloglar, wikiler, etiketleme, yer imleri, medya paylaşımı vb. araç ve uygulamalar), kütüphanelerin bu teknolojilerden faydalanarak "Library 2.0" olarak adlandırılan yeni bir kütüphane ortamının geliştirilmesine katkıda bulunmaktadır.

"Library 2.0", fiziksel ve dijital hizmetlerin oluşturulmasında kullanıcı katılımını sağlayan ve sürekli değerlendirme işlemleri ile desteklenen kullanıcı merkezli bir model olarak tanımlanmaktadır (Casey ve Savastinuk, 2006, s.40). "Kütüphane kaynakları ve hizmetlerinde Web 2.0 teknolojilerinin kullanılması" şeklinde de nitelendirilebilen Library 2.0, kullanıcılarla daha etkili bir iletişimin sağlanması, yeni hizmetlerin sunulması ve kullanıcılar ile olan etkileşimin artırılmasına yardımcı olmaktadır. Abram’a göre (2007) Library 2.0 ayrıca, yeni nesil kütüphane web sitelerinin, veri tabanlarının, intranetlerin, portalların ve OPAC'ların geliştirilmesinde rol oynamaktadır. 
Bilgi hizmetleri açısından incelendiğinde günümüzde kullanıcıların sosyal ağ ortamında, kataloglama ve sınıflama işlemlerini kendilerince gerçekleştirmeleri; web içeriklerine yönelik anahtar sözcükler yardımıyla ontolojiler ve folksonomiler geliştirmeleri; istedikleri kitapların elektronik kopyalarını alışveriş siteleri ya da çevrimiçi yayınevlerinden temin edebilmeleri; kütüphane danışma hizmetleri yerine Wiki'leri kullanmaları; güncel gelişmelerden birbirlerini haberdar etme veya belli konularda görüş paylaşmak için günlükleri (blogs), mikro-günlükleri ya da sohbet odalarını kullanmaları; bilgi kaynakları ve hizmetleri konusunda kütüphanecilerden yardım almak yerine diğer kullanıcıların değerlendirmelerine göre hareket etmeleri olanaklıdır (Tonta, 2009, s.751). Kütüphanelerin geleneksel olarak sunduğu çoğu temel hizmetin, sosyal ağ ortamlarında kütüphanelerden bağımsız şekilde gerçekleştirilmesi, kütüphaneler açısından ilk bakışta kaygı verici olsa da, kütüphane hizmetlerinin sosyal ağ uygulamalarıyla bütünleştirilmesi, bu hizmetlerin etkinliğinin artırılması bakımından oldukça önemli kabul edilebilir.

Çevrimiçi kütüphane katalogları olarak bilinen OPAC'lar (Online Public Access Catalog), kullanıcıların bilgi merkezlerindeki bilgi kaynaklarına erişebilmeleri için en önemli araçlardan biridir. Bu araçlar sayesinde bilgi kaynaklarının bibliyografik bilgilerine, çevrimiçi olarak, zaman ve mekân sınırlaması olmadan ulaşılabilmektedir. İlk olarak 1970'li yıllarda geliştirilen OPAC'lar, MARC (MAchine Readable CatalogingMakinece Okunabilir Kataloglama) formatını kullanarak katalog kayıtlarına bilgisayar üzerinden erişim olanağı sağlamıştır. Birinci nesil olarak adlandırılan bu kataloglar, daha sonra Boolean işlemcileri ve anahtar sözcüklerin kullanılmasına izin veren bir biçimde geliştirilmiştir. 1990'lı yıllarda ortaya çıkan ikinci nesil web temelli kataloglar ise grafik arayüzler ve hiperlinklerin kullanıldığı, arama, erişme ve keşfetme seçeneklerinin daha fazla yer aldığı işlevsel bir yapıya sahip olmuştur (Wilson, 2007, s.406). Genel olarak incelendiğinde, birinci ve ikinci nesil kütüphane kataloglarının sadece bilgi kaynaklarına yönelik kataloglama ve sınıflama işlemleri sonucunda oluşturulan bibliyografik tanımlamalara yer verdiği; kullanıc özelliklerini belirleyen ve geri bildirimleri toplayan bir düzende olmadıkları söylenebilir.

Bugün ise sosyal ağ uygulamalarının etkisiyle kullanıcı beklentilerini karşılayan, kullanıcı özelliklerini belirleyen ve geri bildirimleri toplayan yeni nesil OPAC'ların oluşturulmaya başlandığı görülmektedir. Sosyal ağ uygulamalarının kütüphane kataloglarında kullanılmasına olanak sağlayan yeni nesil OPAC'lar, "ayarlanabilen ilgililik sıralaması", "konu etiket haritaları/bulutları sunma", "arama sonuçlarının genişletilmesi ve filtrelendirilmesi için kümeleme/görüntüleme", "ödünç verme verileri", "diğer kataloglar ve veri tabanları gibi farklı kaynaklardan gelen verileri indeksleme", "yetkeli konu başlıklarıyla ek arama tavsiyelerinde bulunma", "kullanıcı görüşü/etiketleri" ve "doğru hecelenişleri verme" gibi özellikleri bünyesinde bulundurmaktadır (Wilson, 2007, s.407). Bu özelliklere sahip yeni nesil OPAC'lar, web ortamındaki kullanıcıların beklentilerini karşılaması, kullanıcı katılımı/etkileşimini öngörmesi, kullanıcılardan 
elde edilen ek metadata bilgilerini üretmesi, bilgi kaynaklarını keşfetmeyi daha kolay hale getirmesi ve kullanım kolaylıkları sağlaması nedeniyle kütüphane kataloglarının değerini ve işlevlerini oldukça artırmaktadır.

\section{Literatür Değerlendirmesi}

İkinci nesil web olarak adlandırılan Web 2.0 teknolojilerinin web uygulamalarında ortaya çıkardığı değişim ve gelişim, kütüphanelerde bilgi kaynaklarına erişebilmek için en önemli araçlardan biri olan OPAC'ların mevcut yapılarının sorgulanarak yeniden yapılandırılması konusunu da gündeme getirmiştir. Kullanıcıların gereksinim duydukları bilgi kaynaklarını belirlerken OPAC'ların karar verme sürecinde yetersiz kalması ve kullanıcıların beklentilerinin değişmesi, bu yapılandırmanın temel gerekçeleri arasında gösterilebilir. Literatürde yer alan birçok araştırma da bu gerekçeleri özetler ve destekler niteliktedir.

Web 2.0 özelliklerini kullanan sosyal ağ ve kitap satış siteleri (LibraryThing, del.icio.ous, Amazon.com gibi) kullanıcıların kendi dermelerini oluşturmaları ve diğer kullanıcılarla paylaşmalarına, bu dermelere yönelik olarak oylama yapmaları ve görüş belirtmelerine, kendi etiketlerini oluşturarak kendi dermelerine ulaşmalarına uzun zamandan bu yana izin vermektedir. Buna rağmen çoğu kütüphane kataloğu, kullanıcıların kataloglara katılımına bu denli izin vermemekte, sosyal bir yapıyı bünyesinde bulundurmamaktadır (Wenzler, 2007). Ayrıca kütüphane sistemlerinin elektronik bilgi kaynaklarına yönelik olarak kullandıkları OpenURL standardı sayesinde kullanıcılar, OPAC'ları kullanmadan, arama motorları (Google Scholar gibi) veya lisanslı veri tabanları aracılığıyla kütüphane tarafından sağlanan hizmetlere ve kaynaklara kolaylıkla erişebilmektedirler (Coyle, 2007, s.290).

Kaliforniya Üniversitesi Kütüphaneleri Bibliyografik Hizmetler Birimi (Bibliographic Services Task Force, University of California Libraries) tarafından kütüphanedeki bibliyografik hizmetleri değerlendirmek amacıyla hazırlanmış raporda, mevcut kütüphane kataloğunun bilgi kaynaklarını bulma, keşfetme ve seçme işlemleri için zayıf kaldığı vurgulanmıştır (Bibliographic Services Task Force, University of California Libraries, 2005, s.1).

2005 yılında Online Computer Library Center (OCLC) tarafından kullanıcıların kütüphane ve bilgi kaynakları algılarına ilişkin hazırlanan araştırma raporunda, kullanıcıların \%84'ünün bilgiye erişmeye arama motorlarıyla başladıkları ve bu kapsamda sadece \%1'inin kütüphane kataloglarını tercih ettikleri; kullanıcıların yalnızca aradığı bilgi kaynaklarını kütüphanede bulabilme ihtimalini düşündükleri zamanlarda kütüphane kataloglarına başvurdukları ifade edilmektedir (OCLC, 2005).

Wisconsin Üniversitesi Madison Kütüphaneleri'nde (University ofWisconsin Madison Libraries) gerçekleştirilen ve OCLC'nin raporunu destekleyen diğer bir çalışmada geleneksel kütüphane araçlarıyla bilgi kaynaklarını keşfetmenin çoğu araştırmacı için sinir bozucu ve zaman alıcı bir süreci içerdiği sonucu elde edilmiştir (University of Wisconsin Madison Libraries, 2008, s.6). 
Konuyla ilgili önemli çalışmalardan bir tanesi de Breeding (2007) tarafından gerçekleştirilmiştir. Rapor niteliği taşıyan çalışmasında Breeding, OPAC'ların arayüzlerinin karmaşık olduğunu, OPAC kullanımını artırabilecek sosyal ağ yapılarının OPAC'larda bulunmadığını, kullanıcıların OPAC'lardan beklentilerinin çok daha farklı olduğunu ve OPAC'ların fonksiyonlarının geliştirilmesi gerektiğini ifade etmiştir.

OCLC tarafından 2009yılında yayınlanan ve kullanıcıların kütüphane kataloglarından beklentilerini ortaya koyan diğer bir raporda, kullanııların bilgi kaynaklarını keşfetme ve seçme işlemlerinde, kütüphane kataloglarının oylama, görüş belirtme, konularla ilgili kaynaklara yönlendirme ve diğer kullanıcıların listelerini görme gibi özelliklere sahip olmasının büyük faydalar sağladığı vurgulanmıştır (OCLC, 2009).

Chalon, Di Pretoro ve Kohn (2008) tarafından OPAC ve kullanıcılara yönelik olarak yapılan çalışmada, Web 2.0 teknolojilerinin sunduğu "yorum yapma (commenting)", "oylama (rating)", "etiketleme (tagging)", "ödünç verme verilerini içeren kitap önerileri sunma (book suggestion based on loans)", "heceleme önerileri (spelling suggestion)", "fasat arama (faceted search)", "Seçimli Bilgi Duyuru Hizmeti (SDI-Selected Dissemination of Information)" ve "Uygulama Programlama Arayüzü (API-Application Program Interface)" gibi seçeneklerin kütüphane kataloglarında yer alması gerektiği ve bu seçeneklerin kullanıcıların OPAC'ları zenginleştirmesi bakımından önem taşıdığı belirtilmiştir.

Tam, Cox ve Bussy tarafından (2009) yapılan diğer bir çalışmada, Sheffield Üniversitesi'nde öğrenim gören 16 öğrenci ile yarı yapılandırılmış görüşme gerçekleştirilmiş, yeni nesil OPAC'lar hakkında analizler yapılarak öğrencilerin beklentileri saptanmıştır. Bu çalışmada, yeni nesil OPAC'Iarın zaman açısından avantaj ve katalog kullanımında ise kolaylık sağlayacağı sonucu elde edilmiştir.

Yapılan tüm araştırmalar, kullanıcıların beklentilerinin farklı olduğunu, OPAC'lar için kişisel şekillendirmeye olanak tanıyan, kolay kullanılabilen, etkileşimli ve dinamik bir yapının kullanıcılar tarafından benimsendiğini ve OPAC'ların işlevlerinin geliştirilmesi gerekliliğini ortaya koymaktadır.

Kullanıcıların kütüphane kataloglarını şekillendirmesi düşüncesi, temelde kataloglama kuralları mantığına aykırı gözükse de OCLC'nin WorldCat üzerinden sosyal ağları kullanarak gerçekleştirdiği uygulamalar dikkati çekmektedir. Bu uygulamalarda kullanıılar, Worldcat üzerinden taradıkları bir bilgi kaynağını diğer kullanıılarla sosyal ağlar üzerinden (Facebook gibi) paylaşabilmekte, bu kaynak hakkında görüşlerini belirtebilmekte, diğer kullanıcıların görüşlerini ve o konudaki farklı kaynak önerilerini görebilmekte, o kaynağa yönelik kendi etiketlerini oluşturabilmekte, diğer sitelerle (Amazon.com gibi) bağlantı kurarak o kaynağı satın alabilmektedirler. 
Literatürde sosyal ağ uygulamalarının OPAC'larda kullanılmasının çeşitli sorunları da beraberinde getireceği vurgulanmaktadır. Bu sorunlar şu şekilde listelenebilir (HLWIKI Canada, 2010; Steele, 2009, ss. 69-70):

$\diamond$ Standart bir yapının bulunmayışı; bilgi erişim açısından oluşturulan etiketlerin farklı hecelenmelerinde standart bir düzenin olmaması,

$\diamond \quad$ Hiyerarşi ile ilgili sorunlar; konu başlıklarında kontrollü sözlüklerden faydalanarak oluşturulan geniş ve dar kapsamlı terimlerle yapılan ilişkilendirmelerin yapılmadan doğrudan etiket eklemelerinin yapılması,

$\diamond$ Etiketlemede farklı kullanımlar; kullanıcılar tarafından oluşturulan etiketlerde standart olmayan bir şekilde tekil ve çoğul ifadelerin kullanılması,

$\diamond$ Farklı terim ve telaffuzların kullanımı; sosyal kataloglama ile kullanıcılara sunulan dil kullanım özgürlüğünün ortaya çıkardığı tutarsızlıklar,

$\diamond$ Eş anlamlı kelime kullanımları; herhangi bir kontrolün olmaması,

$\diamond$ Kelimelerin çok yönlü kullanımına ilişkin sorunlar; etiketlemede bazı kelimelerin gerçek anlamlarının dışında taşıdıkları anlamlar için kullanılması,

$\checkmark$ Kötü niyetli kullanım; kataloglara eklenecek etiketlerde kullanıcıların içeriğe zarar verecek ifade kullanımları.

Belirtilen tüm sorunlar incelendiğinde "etiketleme" ile ilgili sorunların ön plana çıktığı görülmektedir. Bu sorunlara yönelik olarak "kara liste (black list) uygulamaları", "etiketlerin başka dillerdeki karşılıklarını ifade eden uygulamalar", "ağırlıklandırma algoritmalarının kullanılması", "yapay zekâ uygulamalarından faydalanılarak ontolojiler ve semantik yapıların oluşturulması", "kütüphanelerin/bilgi merkezlerinin denetim mekanizması oluşturması”, "kütüphanelerin/bilgi merkezlerinin konu başlıkları listeleri ve kavram dizinleri (thesaurus) kullanımlarını devam ettirmesi ve kullanıcılara yardımcı bir rol üstlenecek şekilde sunması" çözüm önerileri arasında yer almaktadır (Tarulli, 2010; AquaBrowser, 2010; Steele, 2009, s.72).

Sosyal ağ uygulamalarının OPAC'lara uyarlanması iki yolla mümkün olabilmektedir. Bunlar; açık kaynak kodlu yazılımları/araçları kullanmak ve sosyal ağ uygulamalarının OPAC'larla bütünleştirilmesi için kütüphane sistem sağlayıcılarını ikna etmektir (Wallis, 2009). Bu bağlamda, Vufind, Blacklight, KOHA, SOPAC, OPALS, Evergreen, Scriblio (WPopac) gibi açık kaynak kodlu yazılımların ve Endeca, Primo, Encore, AquaBrowser, OCLC WorldCat Local, Prism, LibraryThing for Libraries, Polaris gibi firmaların sattığı yazılımların, yeni nesil kütüphane kataloglarının oluşturulmasına katkı sağladığı söylenebilir.

Türkiye açısından bakıldığında, sosyal ağ uygulamalarının OPAC'larda kullanılması konusunun oldukça yeni olduğu ifade edilebilir. 2006 yılında Tonta tarafından sunulan bir bildiride, Türkiye'de çevrimiçi kütüphane kataloglarının sosyal ağ uygulamalarından 
faydalanılarak kaynakların içerikleriyle ilgili bilgilere erişim sağlama konusunda yeterli olmadığı belirtilmiştir (Tonta, 2006, s.5). Bugün ise hâlâ OPAC'ların büyük çoğunluğunda sosyal ağ uygulamalarına rastlanmadığı; sadece arama ve görüntüleme seçeneklerinin kullanıcılara sunulduğu görülmektedir. İzmir Yüksek Teknoloji Enstitüsü Kütüphanesi, Özyeğin Üniversitesi Kütüphanesi, Sabancı Üniversitesi Kütüphanesi ve TED Ankara Koleji Kütüphanesi'nde ise sosyal ağ yapılarını içeren yeni nesil OPAC'lara geçiş yapılmıştır. Kullanıcı araştırmaları açısından incelendiğinde ise Türkiye'de kullanıcıların yeni nesil OPAC'lara bakışlarını yansıtan ve beklentilerini saptayan çalışmaların bulunmadığı görülmektedir.

\section{Yöntem}

$\mathrm{Bu}$ çalışmanın odak grubunu Ankara Üniversitesi ve Hacettepe Üniversitesi Kütüphanelerinin kullanıcıları (lisans/lisansüstü öğrenciler ve öğretim elemanları) oluşturmaktadır. Çalışma kapsamında bu iki üniversitenin temel alınmasındaki asıl neden, her iki üniversitede de Bilgi ve Belge Yönetimi bölümlerinin bulunması ve dolayısıyla ilgili konuda kullanıcıların daha bilinçli olabileceğinin öngörülmesidir.

Çalışmanın bulguları, bu kullanıcıların yeni nesil OPAC'lara yönelik bakış açıları ve beklentilerini belirlemek amacıyla geliştirilen yarı yapılandırılmış görüşme formu ile elde edilmiştir. Görüşme formu, ilk olarak 6 katılımcı üzerinde test edilmiş; tekrar geliştirilerek maliyet, zaman ve veri analizi şartları dikkate alınarak 179 kişiye uygulanmıştır. Bu sayı da görüşme yöntemiyle veri toplamak için istatistiksel açıdan yeterli bulunmaktadır. Katılımcıların yaşa ve unvana göre dağılımı Tablo I ve II'de verilmiştir.

Tablo I. Yaş Dağılımı

\begin{tabular}{lcc}
\hline Yaş Grupları & $\mathbf{N}$ & $\%$ \\
\hline $18-22$ & 74 & 41,3 \\
$23-27$ & 57 & 31,8 \\
$28-32$ & 18 & 10,1 \\
$33-37$ & 10 & 5,6 \\
$38+$ & 20 & 11,2 \\
\hline Toplam & 179 & 100,0 \\
\hline
\end{tabular}

Tablo I ve II'deki veriler ışığında, araştırmaya katılan kullanıcıların çoğunluğunun 18-22 yaşları arasındaki lisans öğrencilerinden oluştuğu görülmektedir.

Katılımcılardan alınan yanıtlar, SPSS (Statistical Package for the Social Sciences) programı aracılığıyla değerlendirilmiştir. Sonuç olarak elde edilen tüm bulgular, kullanıcı görüşlerine dayanmakla birlikte üniversitelere genellenememektedir. 
Tablo II. Unvan Dağılımı

\begin{tabular}{lrc}
\hline Unvan & N & $\%$ \\
\hline Öğrenci (Lisans) & 102 & 57 \\
Öğrenci (Lisansüstü) & 27 & 15,1 \\
Araştırma / Öğretim Görevlisi & 23 & 12,8 \\
Yrd. Doç. Dr. & 7 & 3,9 \\
Doç. Dr. & 11 & 6,1 \\
Prof. Dr. & 6 & 3,4 \\
Diğer & 3 & 1,7 \\
\hline Toplam & 179 & 100,0 \\
\hline
\end{tabular}

Bu çalışmanın araştırma soruları ise şunlardır:

$\checkmark$ OPAC'ların elektronik ortamda bilgi aramadaki önemi ve kullanım oranı nasıldır?

$\checkmark$ Kullanıcılara göre OPAC'larda yararlı olabileceği düşünülen sosyal ağ uygulamaları nelerdir?

$\diamond$ Kullanıcıların sosyal kataloglama uygulamalarına aşinalıkları nasıldır?

$\checkmark$ OPAC'ların sosyal ağ uygulamalarıyla bütünleştirilmesinin kullanıcıların OPAC kullanım oranlarına, OPAC'lar üzerinden bilgiye erişmelerine, ilgili bilgi kaynaklarına karar verme süreçlerine nasıl etki edeceği öngörülmektedir?

$\diamond$ Kullanıcılar, yeni nesil OPAC'lara yönelik olarak eğitim gereksinimi hissetmekte midirler?

Araştırmanın hipotezi ise "kütüphane kataloglarının sosyal ağ özellikleri ile bütünleştirilmesi kullanıcıların bilgi erişim süreçlerini olumlu yönde etkilemekte ve çevrimiçi kütüphane kataloglarının etkinliğini artırmaktadır" biçiminde tanımlanabilir.

\section{Bulgular}

Çalışmada ilk olarak kullanıcıların bilimsel bilgiye erişim yolları ve OPAC'lara yönelik görüşleri tespit edilmiştir. Bu doğrultuda kullanıcıların elektronik ortamda bilimsel bilgi ararken kullandıkları yollar arasında ilk sırada; Google, Yahoo Search gibi arama motorlarının (\%64), ikinci sırada konuyla ilgili web sitelerinin (\%39), üçüncü sırada ise OPAC'ların (\%28) yer aldığı saptanmıştır. Bu konuyla bağlantılı olarak kullanıcıların OPAC'lardan hangi sıklıkla faydalandıklarını belirlemek amacıyla sorulan soruya katılımcıların çoğunluğu (\%45) "bazen/dönem içerisinde birkaç kere", \%27'si "haftalık veya günlük düzenli kullanım", \%19'u "dönem içerisinde bir iki defa kullanım", \%9'u ise "hiç kullanmam" yanıtını vermiştir. Ayrıca kullanııılardan OPAC'ların bilgiye erişim açısından yeterlilik düzeylerinin değerlendirilmesi istenmiştir. Kullanıııların yarısı (\%50) yetersiz olduğunu; \%20'si konuyla ilgili bilgisi olmadığını, $\% 30$ 'u ise mevcut düzenleriyle yeterli olduğunu ifade etmiştir. 
Kullanıcıların sosyal ağ ortamındaki kataloglama uygulamalarıyla ilgili farkındalıklarını belirlemek için katılımcılara öncelikle sosyal ağlara (Facebook, Twitter, Myspace vb.) üye olup olmadıkları sorusu sorulmuştur. Çoğunluğunu genç katılımcıların oluşturduğu çalışmada bu soruya katılımcıların \%83'ü "üyeliğim var" şeklinde cevap vermiş̧tir. Bu sorunun ardından kullanıcıların üye oldukları sosyal ağlar içerisinde sosyal kataloglama sitelerinin (LibraryThing, Google Books, Shelfari, Goodreads vb.) olup olmadığı tespit edilmeye çalışılmıştır. Alınan yanıtlar; katılımcıların çoğunluğunun (\%77) herhangi bir sosyal kataloglama sitesine üye olmadığını göstermiştir. Üyeliği bulunan kullanıcılar arasında ise \%22'lik kullanım oranıyla Google Books en çok tercih edilen uygulama olmuş ve bunu \%3'lük kullanım oranı ile LibraryThing izlemiştir. Diğer yandan sosyal kataloglama sitelerine üye olan kullanıcıların bu sitelerde oluşturdukları derme sayılarını belirlemek amacıyla sorulan soruya verilen yanıtlar doğrultusunda, katılımcıların çoğunluğunun (\%67) ilgili ağlarda bir dermeye sahip olmadıkları; dermesi bulunan kullanıcıların ise çoğunlukla (\%25) 1-50 arasında kaynağa sahip oldukları tespit edilmiştir.

Çalışmada sosyal ağ uygulamalarının OPAC'lara uyarlanması ile ilgili kullanıcı görüşlerini almaya yönelik sorulan sorular; bilgi kaynaklarının içeriği (5 soru), bilgi kaynaklarına erişim (6 soru) ve kullanıcı etkileşimi (7 soru) başlıklarını taşıyan üç grup altında toplanarak değerlendirilmiştir.

\section{Bilgi Kaynaklarının Iç̧erikleri}

Araştırma kapsamında, OPAC'lardaki bibliyografik kayıtlarda bulunan tanımlayıcı bilgilerin yanı sıra kaynakların içerikleri ile ilgili hangi bilgilerin bulunmasının ne oranda faydalı olabileceği Likert ölçeği kullanılarak ölçülmüştür. Bilgi kaynaklarının içeriklerine yönelik kullanıcı görüşlerini yansıtan veriler Tablo III'te yer almaktadır.

Tablo III. OPAC'larda Bilgi Kaynaklarının İçerikleri ile İlgili Kısa Bilgilerin Verilmesine Yönelik Görüşler

\begin{tabular}{lcccccccc}
\hline Uygulamalar & & Faydasız & $\begin{array}{c}\text { Az } \\
\text { faydalı }\end{array}$ & $\begin{array}{c}\text { Kısmen } \\
\text { faydalı }\end{array}$ & Faydalı & $\begin{array}{c}\text { Çok } \\
\text { faydalı }\end{array}$ & $\bar{x}$ & S \\
\hline Özet & $\mathrm{N}$ & 3 & 6 & 25 & 68 & 77 & & \\
& $\%$ & 1,7 & 3,4 & 14 & 38 & 43 & 4.17 &, 91 \\
Öz/Abstrakt & $\mathrm{N}$ & 2 & 9 & 32 & 63 & 73 & & \\
& $\%$ & 1,1 & 5 & 17,9 & 35,2 & 40,8 & 4,09 &, 94 \\
İçindekiler & $\mathrm{N}$ & 2 & 6 & 18 & 58 & 95 & & \\
tablosu & $\%$ & 1,1 & 3,4 & 10,1 & 32,4 & 53,1 & & \\
& $\mathrm{~N}$ & 13 & 41 & 67 & 33 & 25 & 3,09 & 1,12 \\
Kapak resmi & $\mathrm{N}$ & 7,3 & 22,9 & 37,4 & 18,4 & 14 & & \\
& $\%$ & & & & & & \\
Önizleme & $\mathrm{N}$ & 4 & 14 & 21 & 72 & 68 & 4,04 & 1,01 \\
seçenekleri & $\%$ & 2,2 & 7,8 & 11,7 & 40,2 & 38 & & \\
\hline
\end{tabular}


OPAC'larda erişilen bir bilgi kaynağının tanımlayıcı bilgilerinin yanı sıra, özet bilgisinin bulunması, kullanıcıların çoğunluğu tarafından (\%43) "çok yararlı" bulunmaktadır. Yararsız olduğunu düşünen kullanıcıların oranı ise \%1,7'dir ( $\bar{x} 4,17)$.

Öz/abstrakt bilgisinin OPAC'larda bulunmasına yönelik olarak sorduğumuz soruya verilen yanıtlar, özet bilgisinin bulunması ile ilgili soruya verilen yanıtlarla paralellik göstermiştir. Bu soruya kullanıcıların çoğunluğu $(\% 40,8)$ "çok yararlı"; \%1,1'i ise "yararsı" cevabını vermişlerdir( $\bar{x} 4,09)$.

Sosyal ağ uygulamalarının OPAC'lara getirdiği bir diğer özellik ise bilgi kaynaklarının içindekiler tablolarının katalog kayıtlarında sunulması olmuştur. Bu doğrultuda kullanıcılara yönelttiğimiz soruya kullanıcıların yarısından çoğu $(\% 53,1)$ "çok yararlı" yanıtını vermiş; bunu \%32,4'lük oranla "yararlı" seçeneği izlemiştir ( $\bar{x} 4,33)$.

Bilgi kaynağının tanınmasına olanak sağlayan kaynak görüntülerine (kapak resimleri vb.) katalog kayıtlarında yer verilmesini kullanıcıların çoğunluğu $(\% 37,4)$ "kısmen yararlı" bulmaktadır. Bu soruda \%22,9'luk oranla "az yararlı" seçeneği ikinci tercih edilen yanıt olurken, "yararlı" ve "çok yararlı" seçenekleri sırasıyla \%18,4 ve \%14'lük oranlarla üçüncü ve dördüncü sırada tercih edilmiştir ( $\bar{x} 3,09)$.

Sosyal ağ uygulamalarının yapılandırıldığı OPAC'ların özelliklerinden bir tanesi de bilgi kaynaklarının içeriklerine erişim sağlayan uygulamaları bünyelerinde barındırmalarıdır. Darien Library tarafından yapılandırılan SOPAC uygulamasında olduğu gibi sosyal OPAC'larda Google Books gibi önizleme sağlayan uygulamaların yer aldığı bilinmektedir. Bu doğrultuda kullanıcılara bilgi kaynaklarının içeriklerine ilişkin önizleme seçeneklerinin katalog kayıtlarında bulunması ile ilgili sorduğumuz soruya katılımcıların büyük çoğunluğu $(\% 40,2)$ "yararlı"; \%38'i ise "çok yararlı" yanıtı vermiştir $(\bar{x} 4,04)$.

Araştırmanın bu bölümünde bilgi kaynaklarının içeriklerine yönelik seçeneklerin OPAC'larda bulunması ile ilgili bulgular genel olarak incelendiğinde, kaynakların içindekiler sayfasının katalog kayıtlarında yer alması seçeneğinin en yüksek yararlılık düzeyine sahip olduğu görülmektedir. Bunu sırasıyla özet ve öz/abstrakt bilgilerinin bulunması seçenekleri izlemektedir. Diğer yandan katalog kaydında bilgi kaynağının görüntülerinin yer alması seçeneğinin "kısmen yararlı" bulunması ve buradaki oranın "az yararlı" bulan kullanıcıların oranına yakın olması dikkat çekicidir.

\section{Bilgi Kaynaklarına Erişim}

Sosyal ağ uygulamalarının OPAC'lara sağladığı önemli özelliklerden bir tanesi de kütüphane dermesine etkin ve çok yönlü erişim sağlamasıdır. Dermelere erişim sağlamada "ilgililik sıralamaları", "fasat yapıları", "etiketleme uygulamaları" ve "heceleme algoritmaları" gibi seçenekler, OPAC'ların kolay kullanılmasına yardımcı olmaktadır. Araştırma kapsamında kullanıcılara bu yönde 6 soru yöneltilerek bu yapıların oluşturulmasının erişim açısından ne ölçüde fayda sağlayacağı belirlenmeye çalışılmıştır. İlgili veriler Tablo IV'te sunulmuştur. 
Tablo IV. OPAC'larda Bilgi Kaynaklarına Erişim Sağlama ile Illgi Görüşler

\begin{tabular}{lcccccccc}
\hline Uygulamalar & & Faydasız & $\begin{array}{c}\text { Az } \\
\text { Faydalı }\end{array}$ & $\begin{array}{c}\text { Kısmen } \\
\text { Faydalı }\end{array}$ & Faydalı & $\begin{array}{c}\text { Çok } \\
\text { Faydalı }\end{array}$ & $\bar{x}$ & S \\
\hline Illgililik sıralamaları & $\mathrm{N}$ & 6 & 18 & 51 & 64 & 40 & 3,64 & 1,04 \\
& $\%$ & 3,4 & 10,1 & 28,5 & 35,8 & 22,3 & & \\
İlgili bilgi kaynağına & $\mathrm{N}$ & 4 & 3 & 25 & 79 & 68 & 4,14 &, 88 \\
$\quad$ yönlendirme & $\%$ & 2,2 & 1,7 & 14 & 44,1 & 38 & & \\
İlgili web kaynaklarına & $\mathrm{N}$ & 12 & 23 & 53 & 63 & 28 & 3,40 & 1,10 \\
yönlendirme & $\%$ & 6,7 & 12,8 & 29,6 & 35,2 & 15,6 & & \\
Diğer basım/çevirilerin & $\mathrm{N}$ & 7 & 19 & 50 & 70 & 33 & 3,58 & 1,03 \\
bilgisi & $\%$ & 3,9 & 10,6 & 27,9 & 39,1 & 18,4 & & \\
& $\mathrm{~N}$ & 4 & 13 & 32 & 67 & 63 & 3,96 & 1,01 \\
Heceleme algoritmaları & $\%$ & 2,2 & 7,3 & 17,9 & 37,4 & 35,2 & & \\
Fasat yapılar & $\mathrm{N}$ & 5 & 10 & 33 & 76 & 55 & 3,93 &, 98 \\
\hline
\end{tabular}

OPAC'larda yapılan arama işlemlerinde sonuçların ilgili mekanizmalar tarafından hızlı ve istenilen biçimde görüntülenmesi önemli bir erişim faktörüdür. Kullanıcılara bu konuyla ilgili olarak yöneltilen sorulardan biri, OPAC aramalarında ilgililik sıralamalarının yapılarak, sonuçların görüntülenmesinin ne derece faydalı olacağı şeklindedir. Soruya verilen yanıtlar kullanıcıların çoğunluğunun $(\% 35,8)$ bu özelliği "yararlı" bulduğunu göstermiştir. Bu özelliği yararsız bulan kullanıcıların oranı ise \%10'dur ( $\bar{x} 3,64)$.

OPAC'lar aracılığıyla bilgi kaynaklarına erişim sağlamak kadar, açık raf sistemi mantığıyla hareket ederek kullanıcılara aranan kaynaklarla ilgili diğer kaynakların gösterebilmesi de önemli bir özellik olarak dikkati çekmektedir. Araştırmada elde edilen bulgular da bu özelliğin kullanıcıların çoğu tarafından "yararlı" (\%44) ve "çok yararlı" (\%38) bulunduğunu göstermektedir $(\bar{x} 4,14)$.

OPAC'larda aranan bir bilgi kaynağıyla ilişkili diğer bilgi kaynaklarına yönlendirmenin yanı sıra, ilgili olabilecek web kaynaklarına da yapılacak yönlendirmeler kullanııılar için faydalı olabilmektedir. Bu yönde sorduğumuz soruya katılımcıların çoğu $(\% 35,2)$ "yararlı" şeklinde yanıt verirken, \%6,7'si "yararsız" şeklinde yanıt vermiştir ( $\bar{x} 3,40)$.

Araştırma kapsamında OPAC'larda bilgi kaynaklarının diğer basım ve çeviri bilgilerinin yer almasının yararlı olup olmayacağı tespit edilmeye çalışııışıtır. Katılımcıların çoğunluğu $(\% 39,1)$ "yararı"ı" şeklinde değerlendirme yaparken, "yararsız" bulanların oranı \%3,9'da kalmıştır ( $\bar{x} 3,58)$.

Bilgi kaynaklarına etkin biçimde erişim sağlamak için yeni nesil OPAC'larda semantik arama yapıları önem kazanmıştır. Bu yapılar, kullanıcıların yaptıkları aramaları "Bunu mu demek istediniz?" tarzı heceleme algoritmaları ile düzenleyerek aramalardaki yanlışların önüne geçmeyi amaçlamıştır. Bu yapıların OPAC'larda yer almasına ilişkin sorulan soruda, kullanıcıların çoğundan (sırasıyla \%37,4 ve \%35,2) "yararlı" ve "çok yararlı" yanıtı 
alınmıştır. Kullanıcıların yalnızca \%9,5'inin "yararsız" ve "az yararlı" seçeneğini tercih ettikleri belirlenmiştir ( $\bar{x} 3,96)$.

OPAC'larda yapılan arama sonuçlarının kategorilere ayrılması ve fasat yapılarının oluşturulması araştırmada ele alınan bir diğer konu olmuştur. Buna göre kullanıcıların çoğunluğu (\%42,5) bu yapıları "yararlı"; \%2,8'i ise "yararsız" bulmuştur ( $\bar{x} 3,93)$.

OPAC'larda bilgi kaynaklarına erişim sağlamaya yönelik olarak elde edilen bulgular; "ilgili diğer bilgi kaynaklarına yönlendirme" özelliğinin diğer özelliklere göre daha yüksek yararlılık düzeyine sahip olduğunu göstermektedir $(\bar{x} 4,14)$. Genellikle yararlı seviyesine yakın ortalamaların elde edildiği bu bölümde, heceleme algoritmaları ve fasat yapılarının yararlılık düzeyinin yüksek olduğu da söylenebilir.

\section{Kullanıcı Etkileşimi}

Sosyal ağ uygulamalarının OPAC'larda kullanılması, kullanıcı etkileşimini esas alan özelliklerin OPAC'lara kazandırılması bakımından önemlidir. Bu sayede kullanıcılar, bilgi kaynaklarına ilişkin kendi etiketlemelerini ekleme, yorum yapma, diğer kullanıcıların yorumlarını okuma, ödünç verme bilgilerini edinme, RSS beslemeleri ve e-posta bilgilendirmelerinden yararlanma gibi birçok olanaklara sahip olmaktadır. Bu bölümde kullanıcı etkileşimine olanak sağlayan özelliklerin OPAC'larda yer alması ile ilgili kullanıcı değerlendirmeleri ele alınmıştır (Bkz. Tablo V).

Tablo V. OPAC'lar Aracılığıyla Kullanıcı Etkileşiminin Sağlanması İle İlgili Görüşler

\begin{tabular}{lllllllll}
\hline Uygulamalar & & Faydasız & $\begin{array}{c}\text { Az } \\
\text { faydalı }\end{array}$ & $\begin{array}{c}\text { Kısmen } \\
\text { faydalı }\end{array}$ & Faydalı & $\begin{array}{c}\text { Çok } \\
\text { faydalı }\end{array}$ & $\bar{x}$ & S \\
\hline Etiket bulutları ve & $\mathrm{N}$ & 6 & 22 & 56 & 66 & 29 & 3,50 & 1,01 \\
etiketleme & $\%$ & 3,4 & 12,3 & 31,3 & 36,9 & 16,2 & & \\
& $\mathrm{~N}$ & 19 & 43 & 61 & 39 & 17 & 2,96 & 1,12 \\
Oy verme (rating) & $\%$ & 10,6 & 24 & 34,1 & 21,8 & 9,5 & & \\
& $\mathrm{~N}$ & 26 & 47 & 60 & 32 & 14 & 2,78 & 1,14 \\
Ödünç verme sayısı & $\%$ & $14,5 \%$ & 26,3 & 33,5 & 17,9 & 7,8 & & \\
& $\mathrm{~N}$ & 21 & 34 & 61 & 46 & 17 & 3,02 & 1,14 \\
Illgili ve ödünç verilmiş & $\%$ & 11,7 & 19 & 34,1 & 25,7 & 9,5 & & \\
bilgi kaynaklarının bilgisi & $\mathrm{N}$ & 6 & 20 & 45 & 70 & 38 & 3,64 & 1,04 \\
& $\%$ & 3,4 & 11,2 & 25,1 & 39,1 & 21,2 & & \\
Yorum yapma & $\mathrm{N}$ & 5 & 18 & 46 & 75 & 35 & 3,65 & 1,00 \\
& $\%$ & 2,8 & 10,1 & 25,7 & 41,9 & 19,6 & & \\
Kişiselleştirme & $\mathrm{N}$ & 6 & 19 & 41 & 69 & 44 & 3,70 & 1,06 \\
\multirow{2}{*}{$\begin{array}{l}\text { RSS beslemeleri ve e-Posta } \\
\text { bilgilendirmeleri }\end{array}$} & $\%$ & 3,4 & 10,6 & 22,9 & 38,5 & 24,6 & & \\
\hline
\end{tabular}


Sosyal ağ uygulamalarının kullanıcılara sağladığı en önemli özelliklerden birisi de, kullanıcıların kendi tanımladıkları arama terimlerini bibliyografik kayıtlara ekleyebilmeleridir. Etiket ekleme ve etiket kümeleri oluşturma özelliği, kullanıcılarla karşılıklı bir etkileşimin sağlanmasına ve kullanıcıların bilgi kaynaklarına erişim olanaklarının artırılmasına yardımcı olmaktadır. Etiket ekleme ve etiket kümeleri oluşturma özelliklerinin OPAC'larda kullanılması ile ilgili sorulan soruya katılımcıların çoğunluğu $(\% 36,9)$ "yararlı" yanıtını vermiştir. Yararsız bulan kullanıcıların oranı ise \%3,4'tür ( $\bar{x} 3,50)$.

Araştırmada bilgi kaynaklarının popülerliğini belirlemeye yönelik oy verme (rating) uygulamalarının OPAC'larda bulunması ile ilgili kullanıcı düşünceleri de alınmaya çalışılmıştır. Buna göre katılımcıların çoğunluğu $(\% 34,1)$ bilgi kaynaklarına yönelik oy verme uygulamalarının OPAC'larda yer almasını "kısmen yararlı" olarak nitelendirmiştir. Bu özelliğin "çok yararlı" olduğunu düşünenlerin oranı ise \%9,5'te kalmıştır ( $\bar{x} 2,96)$.

Kullanıcılarla etkileşimin sağlandığı bir diğer unsur, kaynakların ne ölçüde kullanıldığı bilgisidir. Bu doğrultuda bir bilgi kaynağının kaç kişi tarafından ödünç alındığı bilgisinin OPAC'larda sunulması, kullanıcıların çoğu tarafından (\%33,5) "kısmen yararlı", \%26,3'ü tarafından "az yararlı", \%7,8'i tarafından ise "çok yararlı" görülmektedir ( $\Sigma 2,78)$. Bilgi kaynaklarını daha önce ödünç alan kullanıcıların başka hangi kaynakları ödünç aldıkları bilgisinin OPAC'larda sunulması ile ilgili sorulan soruya ise kullanıcıların çoğunluğu (\%34) “kısmen yararlı", \%25,7'si "yararı”," \%9,5'i ise "çok yararlı”yanıtını vermişlerdir ( $\bar{x} 3,02)$.

Kullanıcıların bibliyografik kayıtlara doğrudan katkıda bulunabilmelerine olanak sağlayan "yorum ekleme / yapılan yorumları okuma" özelliklerinin OPAC'larda yer almasına ilişkin sorulan soruya kullanıcıların çoğunluğu $(\% 39,1)$ "yararlı" yanıtını vermiştir. Bu özellikleri "yararsız" bulan kullanıcıların oranı \%3,4'tür ( $\bar{x} 3,64)$.

Sosyal ağ uygulamalarının OPAC'lara uyarlanması, ayrıca kişiselleştirme özelliklerinin ortaya çıkmasını sağlamıştır. Bu sayede kullanıcıların, kütüphane dermeleri içerisinde kendilerine özgü sanal alt koleksiyonlar oluşturmaları mümkün olmuştur. Bu yapının OPAC'larda bulunması katılımcıların çoğu tarafından $(\% 41,9)$ "yararlı" bulunmuştur. Kullanıcıların sadece \%2,8'i bu yapıların "yararsız" olduğunu belirtmişlerdir ( $\bar{x} 3,65)$.

OPAC'larda sosyal ağ uygulamalarıyla kullanıcı etkileşimin sağlandığı bir diğer unsur ise, RSS beslemeleri ve e-posta bilgilendirmeleridir. Bu sayede kullanıcılar, OPAC'lar üzerinde yapılacak tüm değişikliklerden ve yeniliklerden haberdar olabilmektedir. OPAC'larda RSS beslemeleri ve e-posta bilgilendirmelerinin bulunmasıyla ilgili soruya katılımcıların çoğunun $(\% 38,5)$ "yararı" yanıtını verdikleri görülmektedir. Bu özelliğin "yararsız" olduğunu düşünenlerin oranı ise \%3,4'tür ( $\bar{x} 3,70)$.

$\mathrm{Bu}$ bölümde elde edilen bulgulara bakıldığında, "RSS beslemeleri ve e-posta bilgilendirmeleri", "kişisel derme”, "bilgi kaynaklarına yönelik yorum ekleme / okuma" ve "bibliyografik kayıtlara etiket ekleme / etiket bulutları oluşturma" gibi kullanıcı etkileşimini sağlayan özelliklerin OPAC'larda yer almasının kullanıcılar tarafından yararlı bulunduğu söylenebilir. 


\section{Sosyal Ağ Uygulamalarının OPAC'lara Etkisi}

Araştırmada hangi sosyal ağ uygulamalarının OPAC'larda tercih edildiğini belirlenmenin yanı sıra, sosyal ağ uygulamalarının OPAC kullanımını nasıl etkilediği de tespit edilmeye çalışılmıştır. Bu konudaki veriler Tablo VI'da sunulmuştur.

Tablo Vı. Sosyal Ağ Uygulamalarının OPAC'Iara Uyarlanması ile İlgili Kullanıcı Beklentiler

\begin{tabular}{|c|c|c|c|c|c|c|}
\hline Durumlar & & Katılmıyorum & $\begin{array}{l}\text { Fikrim } \\
\text { Yok }\end{array}$ & Katılıyorum & $\bar{x}$ & $\mathbf{S}$ \\
\hline $\begin{array}{l}\text { Daha az zamanda daha çok bilgi kaynağına } \\
\text { ulaşma }\end{array}$ & $\begin{array}{l}\mathrm{N} \\
\%\end{array}$ & $\begin{array}{l}9 \\
5,0\end{array}$ & $\begin{array}{l}32 \\
17,9\end{array}$ & $\begin{array}{c}138 \\
77,1\end{array}$ & 2,72 & ,55 \\
\hline $\begin{array}{l}\text { Bilgi kaynaklarını belirlemede etkili karar } \\
\text { verme }\end{array}$ & $\begin{array}{l}\mathrm{N} \\
\%\end{array}$ & $\begin{array}{l}11 \\
6,1\end{array}$ & $\begin{array}{l}31 \\
17,3\end{array}$ & $\begin{array}{l}137 \\
76,5\end{array}$ & 2,70 &, 58 \\
\hline $\begin{array}{l}\text { Bilgi kaynaklarının daha etkin ve fazla } \\
\text { kullanımı }\end{array}$ & $\begin{array}{l}\mathrm{N} \\
\%\end{array}$ & $\begin{array}{l}11 \\
6,1\end{array}$ & $\begin{array}{l}32 \\
17,9\end{array}$ & $\begin{array}{r}136 \\
76\end{array}$ & 2,70 &, 58 \\
\hline OPAC'ların daha etkin ve fazla kullanımı & $\begin{array}{l}\mathrm{N} \\
\%\end{array}$ & $\begin{array}{l}8 \\
4,5\end{array}$ & $\begin{array}{l}24 \\
13,4\end{array}$ & $\begin{array}{l}147 \\
82,1\end{array}$ & 2,78 &, 51 \\
\hline $\begin{array}{l}\text { Bilgi kaynaklarına erişimde sosyal ağ } \\
\text { uygulamaları kullanımıyla ilgili eğitim } \\
\text { gereksinimi }\end{array}$ & $\begin{array}{l}\mathrm{N} \\
\%\end{array}$ & $\begin{array}{l}14 \\
7,8\end{array}$ & $\begin{array}{l}38 \\
21,2\end{array}$ & $\begin{array}{l}127 \\
70,9\end{array}$ & 2,63 & ,63 \\
\hline
\end{tabular}

Tablo VI'da görüldüğü gibi araştırmaya katılan kullanıcıların \%77'si sosyal ağ uygulamalarının OPAC'lara uyarlanması ile daha fazla bilgi kaynağına daha kısa sürede erişebileceklerini düşünmektedir. Kullanıcıların \%76,5'i OPAC'ların sosyal bir yapıya kavuşması ile gereksinim duydukları bilgi kaynaklarını belirleme işleminde karar vermenin daha kolay olacağına inanmaktadır. Ayrıca katılımcıların \%76'sı OPAC'larda bu yapının oluşturulmasıyla birlikte bilgi kaynaklarının daha verimli ve fazla kullanılacağını ifade etmekte; \%82'si ise sosyal ağ uygulamalarının OPAC'ların etkisini ve kullanım oranını artıracağını söylemektedir. Araştırma kapsamında ortaya çıkan bir diğer önemli bulgu ise katılımcıların \%71'inin bilgi kaynaklarına erişimde sosyal ağ uygulamalarının kullanılması ile ilgili kütüphane eğitimlerine gereksinim duymalarıdır.

\section{Sonuç ve Öneriler}

Sosyal ağ uygulamalarının OPAC'lara uyarlanması konusunda kullanıcı beklentilerini ortaya koymayı amaçlayan bu çalışmada elde edilen sonuçlar şu şekilde sıralanabilir:

$\diamond$ Kullanıcılar, bilgi gereksinimlerini karşılamak için öncelikli olarak arama motorları ve web sayfalarını tercih etmektedirler. OPAC'lar ise üçüncü sırada kullanılmaktadır.

$\diamond$ Kullanıcıların büyük çoğunluğu, OPAC'ları mevcut yapılarıyla bilgi erişim açısından yetersiz bulmakta ve dönem içerisinde sadece birkaç kez (bazen) kullanmaktadırlar.

$\diamond$ Kullanıcılar, OPAC'ların sosyal ağ uygulamaları ile geliştirilmesi sonucunda; bilgi kaynaklarına daha kolay erişim sağlanacağını, gereksinim duyulan bilgi kaynaklarının belirlenmesinde karar verme sürecinin daha kolaylaşacağını, bilgi kaynaklarının daha fazla ve daha verimli kullanılacağını, OPAC'ların etkin biçimde kullanımının artacağını düşünmektedirler. 
$\diamond$ Kullanıcıların büyük çoğunluğu, etiketleme, yorum yapma, oy verme (rating) gibi birçok özelliği bir arada bulunduran Facebook, Twitter gibi sosyal ağlara üye olmalarına rağmen, sosyal kataloglama sitelerinden faydalanmamaktadırlar. Sosyal kataloglama sitelerinden faydalanan kullanıcıların çoğunluğu Google Books uygulamasından yararlanmaktadır. Buna rağmen bu kullanıcıların çoğunluğunun söz konusu uygulamalarda sanal dermeleri bulunmamaktadır. Bu durum, kullanıcıların çoğunluğunun bu uygulamaları sadece izleyici olarak takip etmek ve önizleme olanaklarından faydalanmak için kullandıklarını göstermektedir.

๑ Sosyal ağ uygulamalarının OPAC'lara uyarlanması sonucunda OPAC'larda bilgi kaynaklarının içeriğini yansıtması bakımından "özet", "öz/abstrakt", "içindekiler tablosu", "önizleme" seçenekleri; bilgi kaynaklarına erişim açısından "ilgililik sıralamaları", "ilgili diğer bilgi kaynaklarına ve web sitelerine yönlendirme", "bilgi kaynaklarının diğer basımlarıve çevirilerineyönelikbağlantılarsunma”,"'heceleme algoritmaları" ve "fasat yapıların sunulması" seçenekleri; kullanıc etkileşimi için ise "etiketleme/etiket bulutları", yorum/görüş belirtme", "kişisel sanal derme geliştirme" ve "RSS beslemeleri/e-posta bilgilendirmeleri" seçenekleri kullanıcılar büyük çoğunluğu tarafından oldukça yararlı bulunmuştur.

$\diamond$ Kullanıcıların çoğunluğu, OPAC'larda bilgi kaynaklarının içeriklerine ilişkin bilgileri veren seçenekleri, bilgi kaynaklarına erişim ve kullanıc etkileşimi ile ilgili seçeneklere göre daha yararlı bulmaktadır.

$\checkmark$ Kullanıcıların büyük çoğunluğu, yeni nesil OPAC'ların bünyesinde bulundurduğu sosyal ağ uygulamalarına yönelik olarak eğitim gereksinimi hissetmektedir.

Elde edilen tüm sonuçlar doğrultusunda kullanıcıların OPAC'larda sosyal ağ uygulamalarından yararlanmak istedikleri söylenebilir. Bu sonuçlar, aynı zamanda OCLC'nin 2009 yılında hazırladığı rapor ve literatürde yer alan diğer çalışmalarla da paralellik göstermektedir.

Sosyal ağ uygulamalarıyla geliştirilen yeni nesil OPAC'lar, kullanıılara etkileşim, katııım ve paylaşım esasına dayanan yeni bir yapı sunmaktadır. Ticari veya açık kaynak kodlu yazılımlar aracılığıyla geliştirilebilen bu yeni yapı, OPAC'ların daha işlevsel ve kullanıcı merkezli olmasına, ayrıca kullanıııların bilgi gereksinimleri için OPAC'lardan daha fazla yararlanmalarına katkı sağlamaktadır. Bu kapsamda, kütüphanelerin kendi kullanıcı gruplarının beklentilerini saptayarak ve ilgili yazılımlardan yararlanarak OPAC'larını gözden geçirmeleri ve geliştirmeleri önerilebilir. Ayrıca belirtilen bu yeni yapıya yönelik olarak tasarlanacak kütüphane eğitimleri, kullanıcıların yeni nesil OPAC'larla ilgili farkındalıklarının artırımasına ve aşinalıklarının geliştirilmesine de yardımcı olacaktır.

\section{Kaynakça}

Abram, S. (2007). Web 2.0, Library 2.0 and Librarian 2.0: Preparing for the 2.0 world. Online Information 2007'de sunulan bildiri. 15 Haziran 2010 tarihinde http://2009.online-information.co.uk/files/ freedownloads.new_link1.1080622103251.pdf adresinden erişildi.

AquaBrowser. (2010). 17 Mayıs 2010 tarihinde http://www.serialsolutions.com/aquabrowser adresinden erişildi. 
Bibliographic Services Task Force, University of California Libraries. (2005). Rethinking how we provide bibliographic services for the University of California. 17 Haziran 2010 tarihinde http:// libraries.universityofcalifornia.edu/sopag/BSTF/ Final.pdf adresinden erişildi.

Breeding, M. (2007). Next-generation library catalogs. Library Technology Reports, 43(4).

Casey, M. ve Savastinuk, L. C. (2006). Library 2.0: Service for the next-generation library. Library Journal, 131(14), 40-42.

Chalon, P., Di Pretoro, E. ve Kohn, L. (2008). OPAC 2.0: Opportunities, developments and analysis. 18 Haziran 2010 tarihinde http://www.terkko.helsinki.fi/bmf/EAHILpapers/Patrice_Chalon_ paper.pdf adresinden erişildi.

Coyle, K. (2007). The library catalog in a 2.0 world. Journal of Academic Librarianship, 33(2), 289-291.

HLWIKI Canada. (2010). Social tagging. 17 Mayıs 2010 tarihinde http://hlwiki.slais.ubc.ca/index. php/social_tagging adresinden erişildi.

Online Computer Library Center. (2005). Perceptions of libraries and information resources. Dublin, Ohio: OCLC.

Online Computer Library Center. (2009). Online catalogs: What users and librarians want. Dublin, Ohio: OCLC.

Steele, T. (2009). The new cooperative cataloging. Library Hi Tech, 27(1), 68-77.

Tam, W., Cox, A. M. ve Bussy, A. (2009). Student user preferences for features of next-generation OPACs: A case study of University of Sheffield international students. Program, 43(4), 349-374.

Tarulli, L. (2010). Social tagging in the catalogue you allowed. 22 Temmuz 2010 tarihinde http:// laureltarulli.wordpress.com/2009/12/30/social-tagging-in-the-catalogue-you-allow-that adresinden erişildi.

Tonta, Y. (2006). Kütüphaneler sanal güzergâhlara mı dönüşüyor? I.Uluslararası Bilgi Hizmetleri Sempozyumunda sunulan bildiri. 18 Haziran 2010 tarihinde http://yunus.hacettepe.edu. tr/ tonta/yayinlar/tonta-istanbul-mayis-2006-bildiri.pdf adresinden erişildi.

Tonta, Y. (2009). Dijital yerliler, sosyal ağlar ve kütüphanelerin geleceği. Türk Kütüphaneciliği, 23(4), 742-768.

University of Wisconsin-Madison Libraries (2008). Resource discovery exploratory task force final report. 17 Haziran 2010 tarihinde http://staff.library.wisc.edu/rdetf/RDETF-final-report.pdf adresinden erişildi.

Wallis, K. (2009). The next generation online public access catalog in academic libraries. Open and Libraries Class Journal, 1(2).

Wenzler, J. (2007). LibraryThing and the library catalog: Adding collective intelligence to the OPAC. 15 Mayıs 2010 tarihinde http://online.sfsu.edu/ jwenzler/research/LTFL.pdf adresinden erişildi.

Wilson, K. (2007). OPAC 2.0: Next generation online library catalogues ride the Web 2.0 wave! Online Currents, 21(10), 406-413. 